\title{
Filming Frenchtown: Listening to and Learning From Storied Lives
}

\author{
Rachel Fendler and Sara Scott Shields
}

\begin{abstract}
This paper explores how teens used storytelling during a yearlong, extracurricular documentary film project. The project invited a group of 8-12 teens and university researchers to act as visual narrative inquirers in a local historic neighborhood. We explore the role of story, framing our project as a form of engaged pedagogy, and draw connections between storytelling and filming. We conclude that at the heart of the project is a shared dialogue. In this project, the scenario of filming enacted an encounter, and came to life through the stories the teens took in, and the stories they produced in response.

This project explores how young people use storytelling to understand and communicate individual and collective stories. Interested in both the physical places people call home and the communities that people define as being at home in (Morley, 2001), a group of young people used video documentary to inquire into these physical and rhetorical homes (Augé, 1995). The project took place over one school year where students acted as narrative inquirers in a local historic neighborhood. The teens initially experienced the neighborhood through walks (Irwin, 2006), then they began informally mapping these walks through film and photography (Powell, 2010). In the final stages of the project, students planned, organized and, in some cases, created documentary videos. Like any good story, we begin with a discussion of the setting, followed by an introduction of the characters and a description of the plot, where we will briefly establish the structure of the learning environment and the pedagogical model informing our project. The paper then moves to the action, where we share the stories the teens documented. Finally, we close with a resolution, where we offer suggestions, reflections, and considerations for how narrative ways of thinking and doing alter educational practice in informal spaces.
\end{abstract}

\section{Setting}

The story of our research and the stories the teens filmed were set in the historic Florida neighborhood of Frenchtown and the city-run Palmer Munroe Teen Center. We cannot say one location was the primary setting and the other secondary; instead, these two locations are interconnected and vital to the project. While the teens were not from the Frenchtown area, they spent almost a year walking, researching, and exploring it. Although the film club initially focused on Frenchtown as a food desert, the project quickly responded to the people we met and the stories they told us.

\section{Teen Center}

About four miles away from Frenchtown is the Palmer Munroe Teen Center (PMTC). The teen center served as the home base for our team of teens. The city of Tallahassee describes the center on its website: 
For years, the Tallahassee community has been asked to provide a place dedicated to teen youth development; a place dedicated to serving some of our most vulnerable youth; a place for teens to expand their opportunities, learn about social responsibility, civic awareness and be gently guided through a restorative justice program. In August 2010, the Palmer Munroe Teen Center opened its doors... [and] offers a unique blend of educational classes, workshops, programs and recreation activities for youth. (Palmer Munroe Teen Center)

Working with teens who frequent the center, our project drew young people from a range of backgrounds. Many of the teen participants attended the teen center after school and on the weekend because the center provides a space for area youth to commune together. PMTC offers opportunities for learning, recreation, and other social supports. The center has a music studio, a small computer lab, several televisions, a communal sitting area, a kitchen, a classroom space, a gym, and a large outdoor playground. The film club, where this project began, was a collaboration between Florida State University's art education department and PMTC. The partnership began in summer of 2016, where teens, armed with cell phones and apps, played with filming a wide range of personal interests. In the Fall of 2016 the project expanded to include several other faculty members and a few new teens. This evolution of membership brought with it some upgraded equipment and access to a computer editing lab on FSU's campus. This is where our story in Frenchtown really begins, armed with a few cameras, microphones, and recording equipment, the teens made their way into the Frenchtown neighborhood.

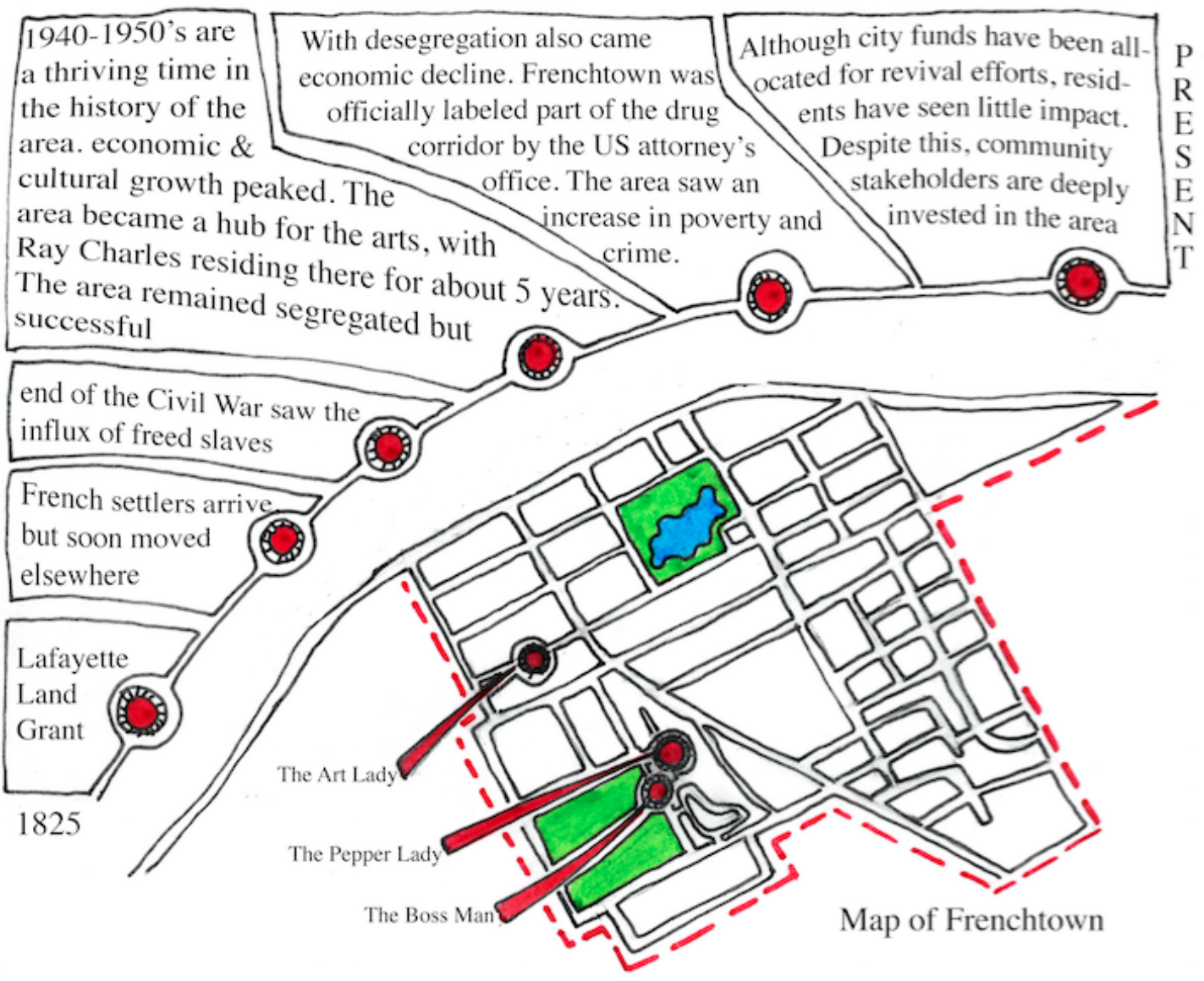

Fig. 1: Map of Frenchtown 


\section{Frenchtown}

Frenchtown's history can be traced to 1825, when French settlers found their way to the area after the Lafayette Land Grant. This settlement was largely unsuccessful, and the French moved, making room for newly freed slaves to find their way to the Frenchtown area. The Frenchtown area was a thriving AfricanAmerican cultural epicenter until the 1960s when desegregation ushered in a period of poverty that still affects the area today (Villeneuve \& Sheppard, 2009). Frenchtown's population is over 4,700, with a majority of the residents identifying as nonwhite. The neighborhood only spans a 0.7 -square-mile area, but remains densely populated, with around 6,700 people per square mile, compared with only 1,900 people per square mile in the greater Tallahassee area (Frenchtown, Tallahassee, FL, 2011). The high concentration of people has supported the development of many embedded community organizations, including a large community garden, a local farmers' market, a community center, several parks, and many local vendors (See: Frenchtown Heritage Hub).

While the history and demographics of Frenchtown are both important and relevant, this project has chosen to focus on the wealth of grassroots community organizations and stakeholders that call Frenchtown home. Early conceptions of this project were interested in having the local teens in our film club work on a film project about food access in the Frenchtown area. Our project began by contacting the Frenchtown Heritage Hub, which hosts a farmers' market and promotes food access, yet it expanded as we simultaneously discovered all the pockets of communities that existed around the Frenchtown area. As the teens explored the community, three specific settings, and their residents, emerged out of students' interests and interactions in the community: a small backyard hot pepper patch (home to The Pepper Lady), the front porch of a neighborhood icon (The Bossman), and a small, independent art gallery (run by The Art Lady).

\section{Characters}

\section{PMTC Teens}

This project was carried out by a group of 8-12 teens. Because the teen center ran as a voluntary afterschool experience, the teens were not required to attend every day. The majority of the teens that participated were Black, with more males usually attending than females. Although the teen center serviced the surrounding neighborhood, not all of the teens were from the area. Over half of the group were from local public schools and four of the teens were homeschooled by their mother. The teens' motivation for participating in film club ranged from teens interested in producing digital media to a more casual association among a few teens who saw film club as a way to interact and spend time with friends.

\section{The Partnership}

Three university faculty members worked on the project with the teens, two from art education and one from the College of Motion Picture Arts. There was also a graduate student researcher from art education 
and several undergraduate researchers from both film and art education backgrounds. The undergraduate researchers attended on a rotating basis to help the teens with editing work, while the graduate researcher was a permanent fixture in the project. The partnership joined the teens with invested faculty and student researchers, providing the space and equipment necessary to work with film in Frenchtown.

\section{The Pepper Lady, Bossman, and Art Lady}

The Pepper Lady, Bossman, and Art Lady are all permanent and committed residents in the Frenchtown neighborhood. While you will hear more about them in later sections, we thought we would introduce their shared background here. All three of these Frenchtown fixtures served as focal points for filming. The Pepper Lady, a lifelong Frenchtown resident, kept a small but productive backyard garden yielding enough peppers to process, jar, and sell hot sauce and spices year-round in the farmers' market. The Bossman, like the Pepper Lady, was born and raised in the Frenchtown area. The Bossman's stories spoke to the racial, political, and cultural nuances of the Frenchtown area. Finally, we meet the Art Lady, a longtime resident, retired school teacher, and assistant superintendent. The Art Lady owns a small gallery in Frenchtown, that she describes as "a place to listen to history" (Gomez, 2014).

\section{Plot}

Imagining pedagogy through the transcendent power of story, we see how much difference, openness, and place matter. As we are quieted by these thoughts, wonders emerge. We wonder, for example, about possibilities for storying and restorying ourselves and one another into being; we wonder about new kinds of, or maybe forgotten or written over, obligations and ways of interacting and responding to and with one another. (Huber, Caine, Huber, \& Steeves, 2013, p. 216)

Overarching the entire project was the notion of engaged pedagogy (hooks, 1994). Engaged pedagogy stands at the intersection of mind, body, and spirit. The whole student and the whole teacher must come to the fore in engaged pedagogical practice. Although this pedagogical approach directly applies to formal learning environments, we see productivity for informal learning spaces. The mutual vulnerability of both formal and informal educational experiences often become one-sided. In contrast to this, we believe all participants should construct educational experiences, allowing for young people to bring their interests and expectations to the project (hooks, 1994). Our experience at the teen center was shaped by an engaged pedagogical approach. While we brought up Frenchtown as a possible site for study, the students ultimately made decisions about who, what, and where we would go. After our informal walking tours, we took time to talk to the teens about what caught their attention. In this way, we relinquished our vision of the project and opened opportunities for the learning experience to be created by the teens. We visited the local community garden, participated in Frenchtown's annual Heritage Festival, walked and danced through neighborhoods, and in the process stumbled down alleyways and wrong turns. The teachers and teens were positioned as students within this process, as we discovered Frenchtown together. 
While the visits began as informal investigations of place, they quickly became more involved. The group wanted to visit the lady that makes the hot sauce; they wanted to find the chickens they saw through a fence one day; they wanted to learn more about the places they glimpsed in our initial walks. As the "grown-ups" in the group, we made those visits happen. We called and arranged a visit with the Pepper Lady at her booth at the farmers' market and later at her house; we found our way back to the neighborhood with the chickens where we met the Bossman; we arranged for the teens to visit the Art Lady at her gallery after attending a social event in her garden. By first exploring the surface and then finding places to dive deeper, the teens found their way into the stories living in Frenchtown. Slowly those stories revealed things about the neighborhood, community, schools, and local government. The connections between the personal lives of the teens and the stories of this neighborhood began to emerge. As the teens created their videos and chatted about the process, we began to see the interconnectedness of the individual, cultural, historical, political, and societal. As we all moved towards the ultimate goal of self-actualization, we found that stories were central to this practice (hooks, 1994).

\section{Narrative as a Pedagogical Approach}

Autobiographical inquiry considers the role of narrative in "reconfiguring of the past in an evolving narrative that makes sense in present circumstances" (Huber et al., 2013, p. 219). By reimagining the past as it influences and affects the present, the storyteller is able to reconsider future actions. Essentially, the telling, retelling, writing, and rewriting of story allows for people to influence their futures (Lugones, 1987), as the storied reverberations from the past move into the present (Huber et al., 2013; Freeman, 2010). We argue that when considering an engaged, narrative, pedagogical approach, the individual story, while important, is really a way for young people to come to a place where they can begin to situate their personal narratives within a broader collective story.

Stories' ability to speak to both the individual and the collective allow them to become a powerful tool when considering pedagogical aims, especially within informal learning environments, where pedagogy is often fluid and changing (Clandinin \& Rosiek, 2007; Huber et al., 2013). We find that, when removed from formal education contexts, the question of learning addresses a broad field, one which has led some authors to approach informal learning in terms of a life-wide project, as captured by Erstad and SeftonGreen's (2013) term "learning lives." Staged as a life project, approaches to learning as life course (Elder, 1998) often look at the role of identity development through processes of reflexive meaning making. This task frequently relies on narrative to relate the meaning of lived experiences (Worth, 2009). Life story and biographical research can capture important moments in ways that can transcend sociological categories, highlighting the complexity of life's transitions (Thomson et al., 2002). In this way, story becomes a pedagogical tool that asks learners to think alongside life's lessons.

Narrative work subsumes the traditional notion of analyzing stories for their content. Instead, the project the teens engaged in was more closely aligned with the notion of collaborative thinking with or through stories (Huber et al., 2013; Morris, 2002). During this project, our group began to: 
construct images of who we are and what we are about, as well as images of who others are and what they are about. Carrying forward these images from across worlds, we gain deeper understandings of ourselves, of others, and of the contexts in which we live. (Huber et al., 2013, p. 219)

In this manner, we experienced how stories allow humans to create their own place in the world while simultaneously making connections to others. Our pedagogical approach pushed the teens to go out into the world and find stories that resonated with them. The teens used other people's stories to think through their own narratives, reconceptualizing their own stories in relationship to the stories of others. This stream of stories became deeper as we (the researchers) returned and rewrote these stories through our own lenses. The stories that follow have journeyed through many filters and have been written, rewritten, and retold many times. We fully acknowledge that these stories, like all good stories, are made up of many lives, voices, perspectives, and influences, allowing them to "entangle with and become shaped by, while at times also shape, social, cultural, institutional, linguistic, and familial narratives" (Huber et al., 2013, p. 227). What we have tried to do in the narratives that follow is first share the stories of the teens and the community they explored, and then share the story of how those experiences contribute to our understanding of the potential for a narrative pedagogy in informal learning environments.

\section{Action}

The following vignettes capture the stories as they unfolded in our project. At the end of each story we link to a teen-produced video that references this encounter or to a video the authors edited, using footage filmed by the teens.

\section{The Pepper Lady}

The Pepper Lady's fame proceeded her. When initially discussing Frenchtown, our teens weren't sure if they knew anything about it. When we mentioned that they have a farmers' market, one teen (JT) chimed in that he knew there was someone there, the Pepper Lady, that made really hot hotsauce. We told him he was right, and shared the one anecdote we knew about her, a comment that was shared by the manager of the farmers' market. Apparently, she had to wear a gas mask when making her sauce, because the fumes it gives off are nearly toxic. Mention of this evolved into a bragging session about how much spice everyone could handle. Ever since, the Pepper Lady was a reference for the group and a starting point to thinking about food production and locally grown food within our project. Early in the project we attended an event hosted in Frenchtown called "Build a Better Block," which brought local residents together in a discussion about neighborhood improvement measures. At a small pop-up market, we found the Pepper Lady with a display of her products. Since we were already equipped with our cameras and microphone, JT approached her for an impromptu interview. She was gracious, and allowed a swarm of teens to gather round to discuss her business, and her peppers. Afterwards, she invited us to visit her place some time. We took her up on the offer. 
JT: So um, what's the pepper do you think to use when, um, you're baking a casserole? PL: A casserole? Well, this is my favorite pepper. This is callend an African Fatalii. It has the heat of the Scotch Bonnet, but in my opinion a lot more flavor. So you do have the heat there, but it's not just mean, its flavorful. So this is one of my favorites that I grow and that I use the most often. I use it in my rice, and salads, I've even made salad dressings with this. So it has about a two-hundred thousand on the score bill.

JT: Nice! So another question, how long have you lived in Frenchtown?

PL: I am forty-nine years old, and I was born in Frenchtown.

JT: Nice!

PL: I moved away, and I came back, and I built a house across the street from my mom. I'm still in my old neighborhood, Goodbread.

[After an in-depth conversation that entailed swapping recipes and talking pepper varieties, we prompt JT to finish up.]

AUTHOR: Do you have a final question, JT?

JT: OK. Well, can I give you a hug?

PL: Sure!

JT: That's my final question! Can I give you a hug! [Laughs]

We learned through trial and error that traveling into Frenchtown without the cameras was a disappointment. After that first meeting, we arranged a visit with the Pepper Lady, and went to talk with her without bringing our cameras along. Our goal for this meeting was to attend to our host and gather information that would then influence the documentary films currently in development. Instead, we witnessed the teens disengage from the process, apparently bored with the conversation as they assumed a role of passive listening while doodling, talking amongst themselves, and asking few questions. A return trip with the cameras was markedly different. JT again carried out an interview with the Pepper Lady, this time with a prepared list of questions. He was accompanied by two cameras and a floating microphone on a boom pole. On another occasion, it was the sight of a group teens wandering the neighborhood with cameras that made one person stop, inquire about our project, and invite us to chat with him in his home. The cameras caught the Bossman's attention and led us into his house, and into his story. We came to witness how the film equipment bestowed on the teens a professional confidence, allowing them to request interviews, ask follow-up questions, and even enter the homes and private gardens of the people that engaged with us. The presence of the cameras provided an entry-point that connected our wanderings through Frenchtown with the local community. 


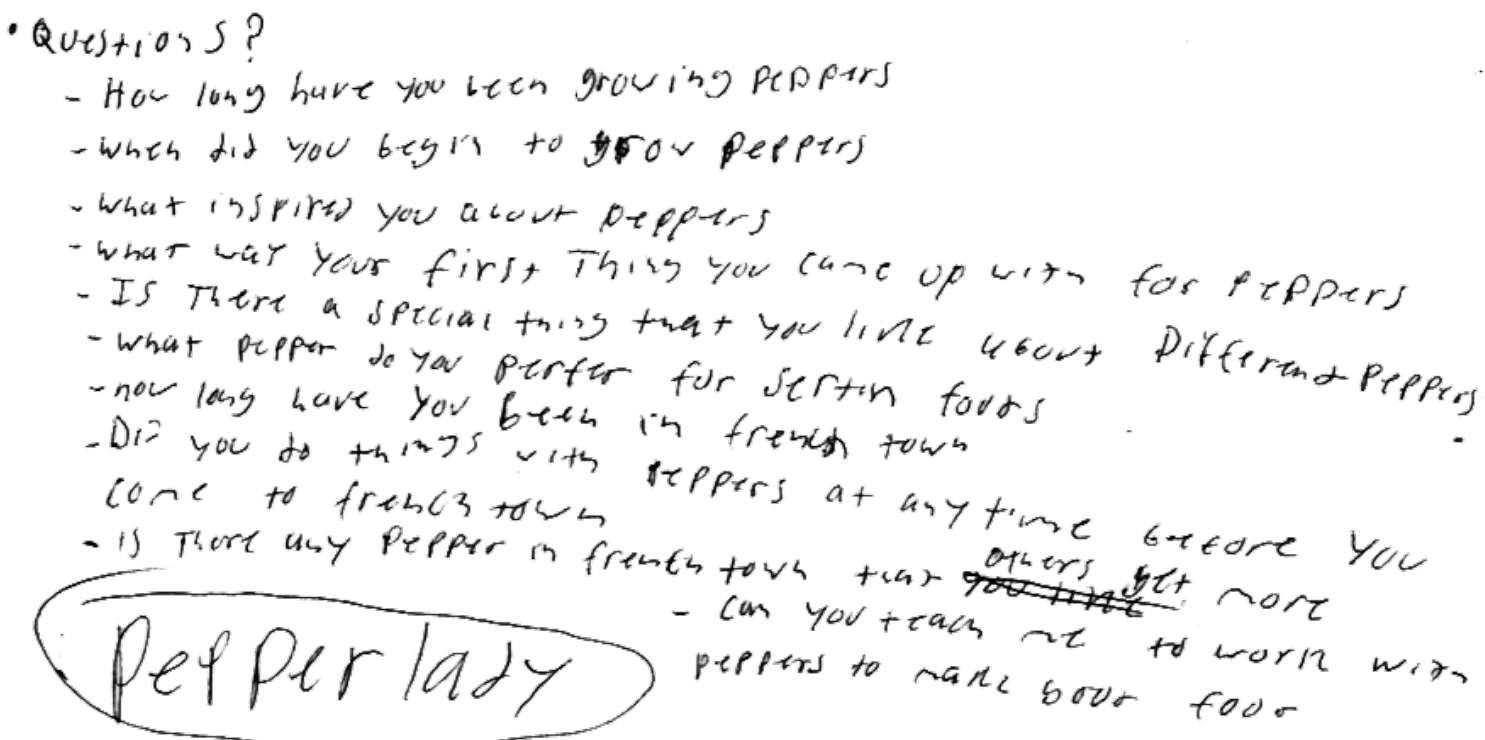

Fig. 2: Questions

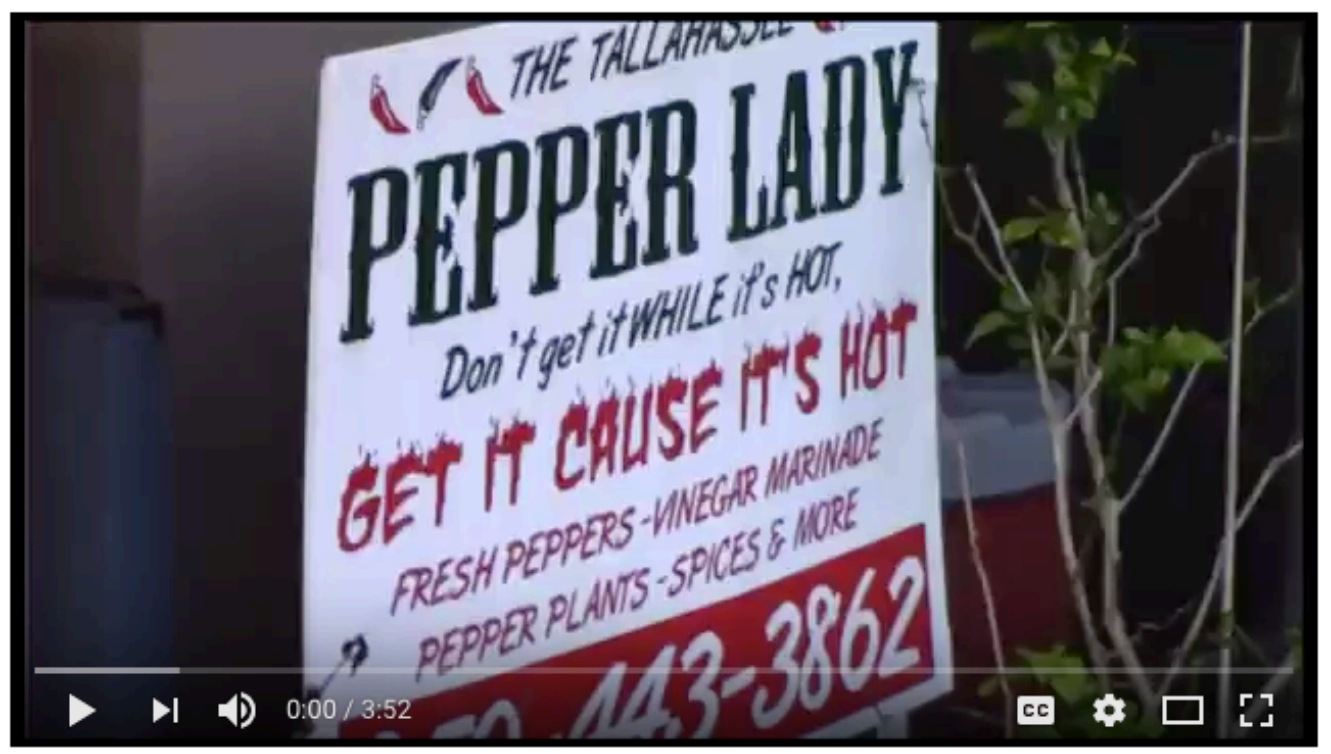

Fig. 3: F-Cubed interview with the Pepper Lady [Video contribution edited by the authors, using teen footage: https://youtu.be/onQ0Aj-MAjQ]

\section{The Bossman}

The white sign cheerfully welcomed us to the Goodbread neighborhood. We had been several times, looking for the chickens we had caught glimpses of through fences and bushes. We found the hen, slowly meandering their way around the neighborhood. A woman stepped out on her porch, "what ya'll doing?" We walked over to tell her about our film club and see if she knew anything about the chickens. She introduced herself, told us the chickens lived in a house at the end of the neighborhood. She was pretty sure it was a rental, filled with too many college students. She told us they used to have a 
pig, but the city had come to pick him up. We thanked her for chatting with us and, with cameras still rolling, we made our way back to the neighborhood's front entrance. A truck slowed, a heavyset Black man leaned out the window, "Why don't you all come right up here and sit on the porch?" He pointed to a house just out of view. As the truck sputtered off we made our way to The Bossman's front porch. When we walked up the steps the front door was propped open with the smell of cooking food wafting out. He invited us in, told us to sit down and get comfortable.

Bossman: White people stayed on the East side of Bronough street, so that wasn't Frenchtown...all of that was White. The way that it got to be expanded from that area to Basin [?] street and up to Tharpe street was when they come up with all this community money. When they got this two million dollars to glorify, beautify your neighborhood. And they said you got to have x number of acres, $x$ number of people and all that. That's when Frenchtown went from Brevard and Tharpe and all that. But the people on the other side of $4^{\text {th }}$ Avenue, they don't know nothing about it. They put a sign one time that said Levy Park neighborhood. That was never Levy Park, that was called Sunnyland... That's not Levy Park, Levy Park was the playground, that was called Sunnyland. Those were the poorest White people in all of Tallahassee. If you walked in that neighborhood you couldn't walk on the sidewalk, you had to walk in the middle of the street. And you had to have a little trot coming through... now the only Blacks that lived on the north side of $4^{\text {th }}$ were the Coopers, you've probably heard of Dr. Gerald Cooper... But that's not Frenchtown. And they trying to rewrite history to purposefully get the money, but it's not a part of it, it's not. It's not... You had two main [White] neighborhoods in Tallahassee, Sunnyland and Los Robles. Los Robles was where all the rich White families lived. My momma worked back there when she was younger, and right there at the gates of Los Robles, my dad couldn't walk through there to walk her home when she was younger... so he stood at the gate of Los Robles and then walked her home. (The Bossman interview transcript)

In our final conversation at the end of this project, we asked the teens what their favorite part of the filming had been and several of the teens shared that the visit with the Bossman was particularly seminal because they learned about a time in history where Black people and White people lived separate lives. The teens went on to talk about how shocked they were to hear about how the neighborhood transitioned as integration happened and how that challenged their understanding of what it meant to be Black. One teen shared how surprised they were that, "we had to drink from different water fountains, and walk on different sidewalks." As a group of predominantly Black teenagers, many of them had been unaware of how different life once was for people with bodies and skin that looked like theirs. One of the participants looked at one of the authors and said, "Life was so different for Black people, when, no offense [AUTHOR NAME], White people weren't so nice." In the final days of the project we realized that the collective identity beginning to form was not necessarily one rooted in Frenchtown or Tallahassee, but rather this film project had been an experience in developing identities as Black "agental" teenagers. 


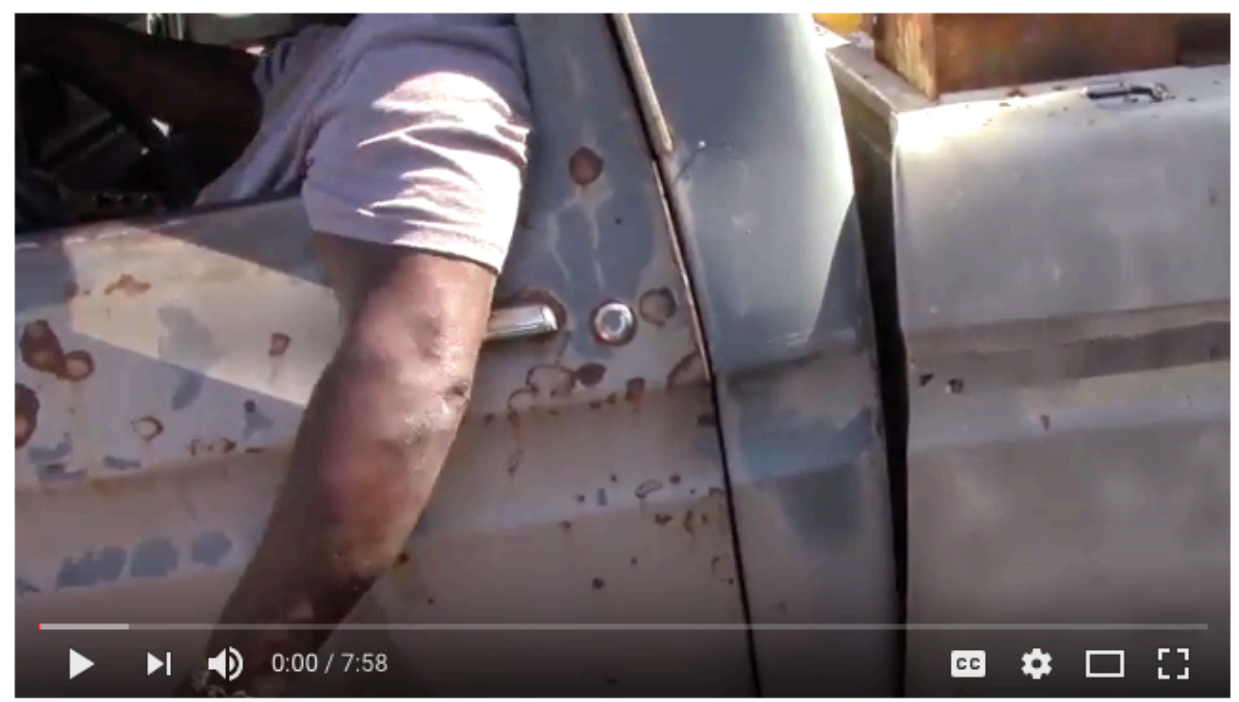

Fig. 4: F-Cubed: Interview with the Bossman [Video contribution by teen participants: https://youtu.be/g8SY4UcsnTc]

\section{The Art Lady}

The Ash Gallery is a cheery green house that sits on Georgia St., which is a site of an urban renewal project in Frenchtown where traditional, single-family homes have been restored. The Art Lady arrived in Frenchtown during this period of renewal and describes the work she put in to fixing up the gallery and eventually her home, next door. Today, her space has a lush garden in the back, which hosts community events. We first encountered the Art Lady at such an event, when we attended a meeting for the "Build a better block" initiative, led by the city and the Rural and Urban Planning Department of a local university. She invited us back to her garden and we took her up on the offer. The story she told wove together her personal history with the socio-cultural history of the neighborhood. She got to know Frenchtown in the 60s while attending the local Historically Black College, Florida A\&M University. She became a teacher at a local high school, hired as part of the process of integration, before becoming the second female Assistant Superintendent of Leon County Schools, then moved away from Tallahassee to central Florida. When she returned to the area 15 years later, the neighborhood was overgrown and abandoned. At that time no one supported her decision to move to the center of Frenchtown; she told us she is proud to have committed to this area and to have participated in its improvement. The Art Lady discussed her move to Frenchtown as one that relied on "sweat equity," communicating to our group both the history of urban Black communities in the 80s and 90s, while also providing tips for generating and maintaining wealth within Black communities, such as buying fixer-uppers for housing or independently owned businesses. While this discussion around history and how it has affected Frenchtown was interesting to the authors, when it came time to ask questions, the teens focused on the Art Lady's art practice. Essentially, they wanted to know: how does someone become an artist?

Don't be afraid of a right or wrong, because art is what you see. And one of the things I like to do, I like faces, but I remember when I first got started, it looked warped to me. [Laughs] ... I wrap stones, I do beadwork. I didn't go to school for any of that. I had this man, I saw him doing the little 
drops around the neck. And I asked him to teach me. It was at a flea market in [unclear]. He said to me, 'Well come on over, I'll show you.' He wrapped the stone, and then he gave me one. And he said, 'When I see you again, show me what you did with it.' Well, honey, he was shocked! I came back, I had wrapped that stone, I had pearls hanging off of it! He was like, 'What did you--?' And I was like, 'I don't know, I didn't like it plain.' So you just-- If you like art, go into the art store... and just ask questions, and get started. You have to just get started. (The Art Lady interview transcript) Our meeting with the Art Lady provided a lot of background information about the history of Frenchtown, but what resonated with the teens was the experience of having met and talked with an artist. We found out during our conversation with the Art Lady that one of the teens painted and wanted to go to art school, a fact that hadn't come up previously, despite almost eight months of collaborating. Other teens also shared their own proclivities for artmaking and we lingered inside the gallery itself, a treasure trove of colorful, painted bottles, windows, canvases, and other restored objects. Hearing the story of the Art Lady created an opening for teens to share their own passions and hopes for the future. Our interview with her didn't spark an intense interest in the past, but instead connected with a desire many of the teens held on to. This encounter invited teens to imagine themselves differently, perhaps as artists, or perhaps as young people who have the capacity to mold their life into something purposeful, just as the Art Lady had.

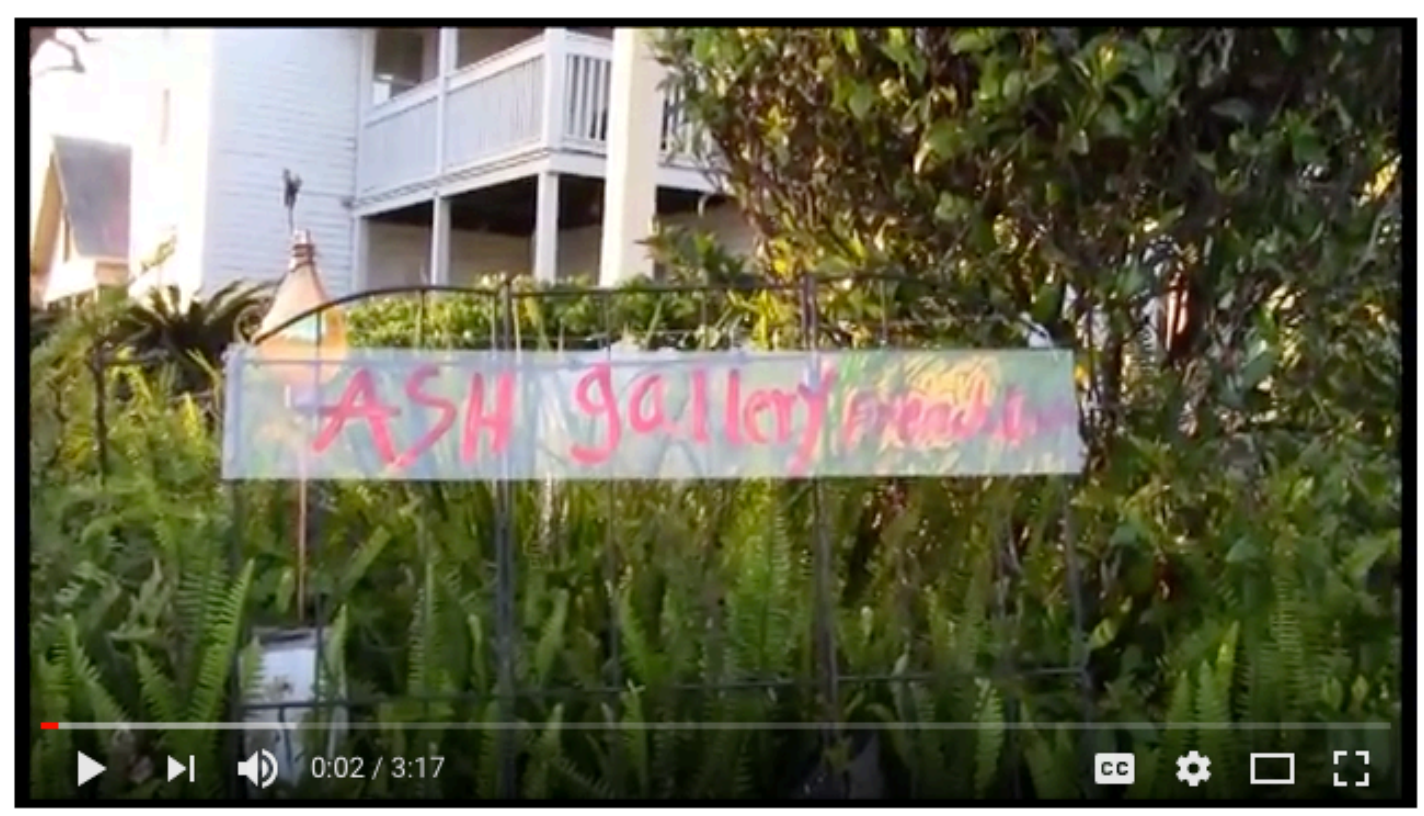

Fig. 5: F-Cubed interview with the "Art Lady" [Video contribution edited by the authors, using teen footage: https://youtu.be/eHVdqpHSB8A]

Although the social issue of food access catalyzed this documentary project, what captured the teen filmmakers' attention were the people we met along the way. The stories residents shared gave us a sense of place and rooted the filming process in a meaningful, personally relevant exploration of identity. The move away from food access to a more open-ended exploration of Frenchtown embodies our interpretation of engaged pedagogy, where hooks (1994) reminds us that teachers have the responsibility to respond to learners' expectation that we "will not offer them information without addressing the 
connection between what they are learning and their overall life experiences" (p. 19). It was through story that our group, adults and teens, gained insight into the lived history of Frenchtown. At the same time, it was notable how much the invitation to respond to these stories through multimodal forms of expression (Kafai \& Peppler, 2011) affected the project. Encountering the Frenchtown stories from an active position of cultural producers (Fendler \& Hernández-Hernández, 2015; Jenkins, Clinton, Purushotma, Robinson, \& Weigel, 2006) set the scene for a high level of engagement. Carrying cameras, teens were not just listening but honing their personal lenses; they not only responded to, but also expanded on the stories we found, adding their own experiences, reflections, and stories within the emergent living history of this neighborhood.

\section{Resolution}

In discussing the role of narrative as a life-wide pedagogical process, Braidotti (2006) reminds us that our "capacity to endure is collective, it is to be shared. It is held together by narratives, stories, exchanges, shared emotions and affects" (p. 199). In our case, the act of filming played a central role in developing a collective encounter in Frenchtown, one that led the teens to reflect on both their community and their own intertwined sense of place and self. Of particular interest is the role film played in this opportunity for storytelling. We found that the video camera asked the teens to bestow a specific type of attentiveness toward their setting, as it directed the teens toward an unfolding narrative.

Film is typically a narrative medium, but the stories told in the final films the teens created do not follow traditional plot devices. Wandering into the stories told by the Pepper Lady, the Bossman, and the Art Lady, the teens listened, recorded, and moved on. Their final films documented our practices of being in Frenchtown, including the interviews and stories alongside the improvised "parkour," dancing, and trips to the local community garden that also took place during our excursions. The stories that emerged through the lens of the teens' perspective tell of their own experience and do not reproduce a report on the experience of those we encountered. This demonstrates a productive intersection between the starting point of our documentary project, which resembles life story research, and an end point, which tells the story of our unfolding exploration of the neighborhood.

At the end of our project, the teens edited several short films: a Pepper Lady film, a Bossman film, one about iGrow, the local community garden, and a long "making of" set to music, among others. The use of film in educational and community settings can provide insights into thinking about and complicating the narrative role of documentary film. Ethnocinema is a term that Harris $(2012 ; 2014)$ uses, which positions collaborative filmmaking as a critical pedagogical practice that engages participants in border crossing (Giroux, 1991) and opens up the possibility for new hybrid identity work in a third space (Bhabha, 1994). For Harris (2014), ethnocinema is a use of video that becomes "a record of intercultural relationships... which is mutual, artistically and socially transformative" (p. 551). In her work, Harris shifts the focus from the content of film to the practice of filming, highlighting film as a record of the relationships that were established during production. Such films do not need to reproduce a traditional, journalistic form of documentary. Rather, Harris's approach to ethnocinema reframes video 
work as the documentation of affective encounters, which engage people on both sides of the lens in a project that "demands sharing and listening" (p. 555). In their review of community-based media programs, Grauer, Castro, and Lin (2012) affirm that all filmmaking is a collective endeavor and, "in a group of young filmmakers, the collaborative nature of community is significant in affirming and cultivating alternate ways of knowing" (p. 148). Both Harris (2014) and Grauer et al. (2012) point to an emerging quality in our project, where the work of filming led teens into an exchange with the stories of others. However, reproducing these stories for a film audience was not the end goal. The final films are ultimately a register of the filmed encounter.

To this end, we find that the open-ended artistic encounter with Frenchtown may have a visual result, but the impact of the project was the experience. O'Donoghue (2015) revisits Dewey's suggestion that art is experience, by suggesting that art practice:

creates the conditions, for those of us who are open to the possibility of being seduced and cajoled and made different by them, to come to know ourselves in the strangeness of ourselves as we do things that we would not do habitually... [Art] works and our participation in them create an occasion for us to come in contact with, or encounter, our learning selves and to feel ourselves becoming and unbecoming. (p. 110)

We know through narrative inquiry that stories are what make our lives, our experiences, meaningful (Clandinin \& Connelly, 2000). Throughout our project, we suspected that video provided the teens an excuse to engage in the making of stories, through dialogue and conversation. The final films speak to this, offering glimpses into our encounters, our meanderings, and generally showing what happened to us during the 10 months in which this project took place. Collectively, this body of work tells the tale about how our collaborative project engaged with stories, allowing them to orient our knowledge of Frenchtown, and ultimately, how these stories influence the ongoing project of our learning selves.

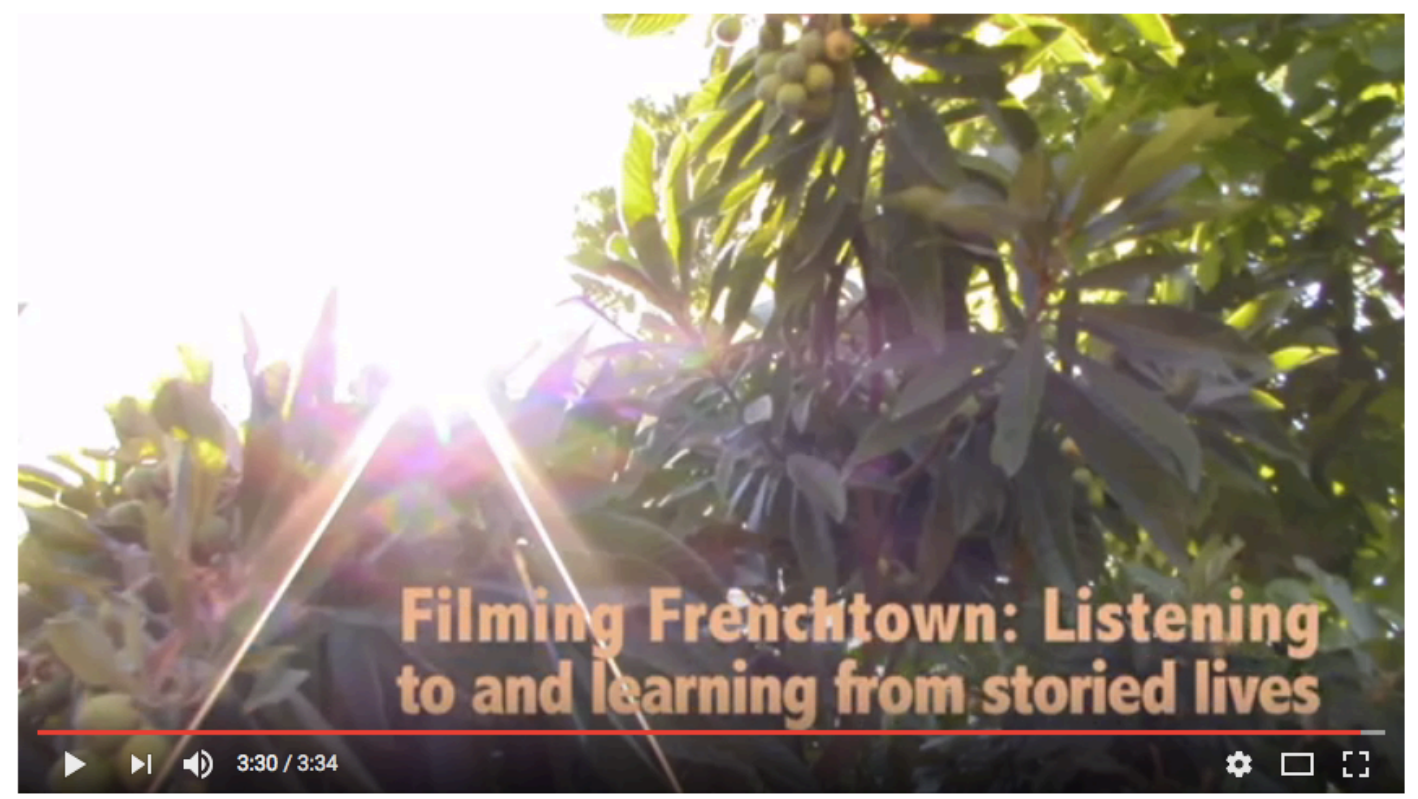

Fig. 6: Filming Frenchtown: Listening to and learning from stories lives [Video contribution edited by the authors, using teen footage: https://youtu.be/XxTTUxIvnsA] 


\section{References}

Augé, M. (1995). Non-places: towards an anthropology of supermodernity. (Trans. John Howe). London: Verso.

Bhabha, H. (1994). The location of culture. London: Routledge.

Braidotti, R. (2006). Transpositions: On nomadic ethics. Cambridge: Polity Press.

Clandinin, D. J., \& Connelly, F. M. (2000). Narrative inquiry: Experience and story in qualitative research. San Francisco, CA: Jossey-Bass.

Clandinin, D. J., \& Rosiek, J. (2007). Mapping a landscape of narrative inquiry: Borderland spaces and tensions. In D. J. Clandinin (Ed.), Handbook of narrative inquiry: Mapping a methodology (pp. 35-75). Thousand Oaks, CA: Sage.

Elder, G. H. (1998). The life course as developmental theory. Child Development, 69, 1-12. doi:10.1111/j.1467-8624.1998.tb06128.x

Erstad, O., \& Sefton-Green, J. (Eds.). (2013). Identity, community, and learning lives in the digital age. New York, NY: Cambridge University Press.

Fendler, R., \& Hernández-Hernández, F. (2015). Visual culture as living inquiry: Looking at how young people reflect on, share and narrate their learning practices in and outside school. In Imanol Aguirre (Ed.), mor thN img cnsmrs: Mapping and evaluating research on young people as visual culture producers (pp. 281-297). Pamplona, Spain: Public University of Navarra.

Freeman, M. (2010). Hindsight: The promise and peril of looking backward. New York, NY: Oxford University Press.

Frenchtown, Tallahassee, FL. (2011). Neighborhood boundary data [data set]. Retrieved from http://www.city-data.com/neighborhood/Frenchtown-Tallahassee-FL.html

Frenchtown Heritage Hub. (n.d.) Retrieved from http://www.frenchtownheritage.org

Giroux, H. (1991). Border pedagogy and the politics of postmodernism. Social Text 28, 51-67.

Gomez, M. (2014, June 26). Art-wielding Activist Annie Harris is Changing the Face of Frenchtown [Blog post]. Retrieved from http://blogs.tallahassee.com/community/2014/06/26/artactivistannieharris

Grauer, K., Castro, J.C., \& Lin, C. (2012). Encounters with difference: Community-based new media programs and practices. Studies in Art Education, 53(2), 139-151.

Harris, A. (2012). Affect and the social imaginary in ethnocinema. In P. Burnard, E. Mackinlay, \& K. Powell (Eds.), The Routledge handbook of intercultural arts research (pp. 81-90). New York, NY: Routledge.

Harris, A. (2014). Ethnocinema and the impossibility of culture. International Journal of Qualitative Studies in Education, 27(4), 546-560. doi:10.1080/09518398.2013.775377

hooks, b. (1994). Teaching to transgress: Education as the practice of freedom. New York, NY: Routledge.

Huber, J., Caine, V., Huber, M., \& Steeves, P. (2013). Narrative inquiry as pedagogy in education: The extraordinary potential of living, telling, retelling, and reliving stories of experience. Review of Research In Education, 37(1), 212-242. 
Irwin, R. L. (2006). Walking to create an aesthetic and spiritual currere. Visual Arts Research, 32(1), 75-82.

Jenkins, H., Clinton, K., Purushotma, R., Robinson, A. J., \& Weigel, M. (2006). Confronting the challenges of participatory culture: Media education for the 21st century. Chicago, IL: MacArthur.

Kafai, Y. B., \& Peppler, K. A. (2011). Youth, technology and DIY: Developing participatory competencies in creative media production. Review of Research in Education, 35(1), 89-119.

Lugones, M. (1987). Playfulness, "world"-travelling, and loving perception. Hypatia, 2(2), 3-19.

Morley, D. (2001). Belongings: Place, space and identity in a mediated world. European Journal of Cultural Studies, 4(4), 425-448.

Morris, D. B. (2002). Narrative, ethics, and pain: Thinking with stories. In Charon, R., Montello, M. (Eds.), Stories matter: The role of narrative in medical ethics (pp. 196-218). New York, NY: Routledge.

O'Donoghue, D. (2015). The turn to experience in contemporary art: A potentiality for thinking art education differently. Studies in Art Education, 56(2), 103-113.

Palmer Munroe Teen Center. (n.d.). Retrieved from http://www.talgov.com/parks/centers-palmer.aspx.

Powell, K. (2010). Making sense of place: Mapping as a multisensory research method. Qualitative Inquiry, 16(7), 539-555.

Thomson, R., Bell, R., Holland, J., Henderson, S., McGrellis, S., \& Sharpe, S. (2002). Critical moments: Choice, chance and opportunity in young people's narratives of transition. Sociology, 36(2), 335-354. doi:10.1177/0038038502036002006.

Villeneuve, P., \& Sheppard, D. (2009). Close to home: Studying art and your community. Art Education, 62(1), 6-13.

Worth, N. (2009). Understanding youth transition as 'Becoming': Identity, time and futurity. Geoforum, 40(6),1050-1060. doi:10.1016/j.geoforum.2009.07.007.

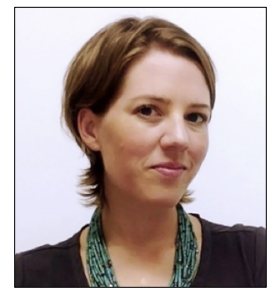

Rachel Fendler, PhD, is an Assistant Professor of Art Education at Florida State University, where she is the Director of Online Programs. She received her MA in Visual Studies and PhD in Art Education from the University of Barcelona. Her research interests include youth visual culture, participatory research with young people, and video as method. This line of inquiry focuses on the role visual and artistic production play in supporting different modes of youth agency.

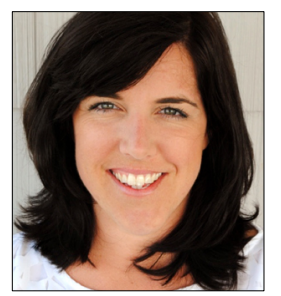

Sara Scott Shields, PhD, is an Assistant Professor of Art Education at Florida State University. She currently serves as Director of the Masters in Art Education program. She received her $\mathrm{PhD}$ in Art Education from University of Georgia. Her research interests revolve around arts-based approaches to both research and learning, with a specific focus on arts-informed qualitative research methodologies, artful pedagogy in higher education, and teacher/researcher identity development. 
Rachel Fendler and Sara Scott Shields

156 | LEARNing Landscapes | Spring 2018, Vol. 11 No. 2 